\title{
Comparison of immunisation rates in general practice and child health clinics
}

\author{
Jun Li, Brent Taylor
}

\author{
Abstract \\ Objective-To compare immunisation uptake \\ rates in general practice surgeries and community \\ child health clinics.
}

Design-Cohort study using data from a computerised child health system.

Setting-Four health districts of North East Thames Regional Health Authority.

Subjects-3616 children born January to March 1990 and resident in the four districts at the end of January 1991.

Main outcome measures-Immunisation uptake rates at $\mathbf{1 0 - 1 2}$ months of age, age at immunisation, scheduling performance at the two locations, and odds ratios of outstanding immunisations.

Results $-80 \%$ of children registered at general practices had completed their third dose of pertussis immunisation compared with $68 \%$ of those at health clinics. Median ages at the third dose were 24 weeks and 29 weeks at the two locations respectively. Scheduling was more effective at general practice surgeries. Unscheduled immunisations were more likely to be given after the recommended age. Overall, children resident in rural and suburban areas had greater uptakes than those in inner cities. Odds ratios for not being fully immunised among children registered at health clinics were 1.4 times those among children immunised in general practice and 3.0 times greater among children resident in inner cities than among those in rural and suburban districts. Children who moved into a district, however, were no less likely to be fully immunised than children who were born there.

Conclusions - The immunisation uptake rate was better in general practices than in child health clinics in both inner city and rural and suburban areas. Uptake may be increased with additional support to enable general practitioners to undertake immunisations, especially in inner cities.

\section{Introduction}

In Great Britain children are usually vaccinated either at a community health clinic or centre or at a general practice, a few being immunised opportunistically in hospital wards. ${ }^{1}$ Normally, shortly after a baby is born the parents receive and sign a consent form which indicates preference for their child's immunisations to be done at a general practitioner's surgery or at a community health clinic.

Immunisation uptake in the United Kingdom is improving in association with various strategies, ${ }^{2}$ including the computerisation of child health systems. ${ }^{3}$ Nevertheless, uptake is still below the targets set by the World Health Organisation and in European countries. ${ }^{+}$Factors associated with the low uptake include social and family characteristics, attitudes of health staff and parents towards the immunisation and the diseases, and health care organisation..$^{5.8}$

The child health system, which has been computerised in most health districts in Britain, ${ }^{2}$ produces an appointment invitation based on the immunisation schedule and the child's age. The appointment is posted direct to the parents or may be sent via the general practitioner or health clinic. When an immunisation is done detailed information on the immunisation is always asked to be fed back to the child health computing system. Relevant information on a child who moves into a district, including immunisation history, is provided by the previous district health authority, transferred general practitioner records, or the health visitor responsible for the child and the data entered into the computing system.

We have compared the uptake rates of immunisation among children registered at general practitioner surgeries with those among children registered at community child health clinics using data from a computerised child health system in four health districts of North East Thames Regional Health Authority.

\section{Subjects and methods}

We studied four health districts in the North East Thames region, which has developed a child health computing system, the North East Thames Regional Interactive Child Health System. This system, similar to the national standard child health computer system, ${ }^{9}{ }^{10}$ provides various information on individual children. To facilitate the comparisons districts were categorised on sociodemographic and geographical determinants into two types, rural and suburban and inner city areas, each type including two districts.

The study children were born between January and March 1990 and resident in the four districts at the end of January 1991. All the data on these children (aged 10-12 months) were derived anonymously from the computer system after permission had been obtained from district managers and directly responsible staff in each of the four districts. This cohort of children was divided into two groups, those registered at a general practitioner's surgery and those registered at a community child health clinic for their immunisations. There was a small proportion of children (154 out of $3770 ; 4 \cdot 1 \%)$ whose data on vaccination location were not available in the child health system. These children were excluded from our analyses.

The recommended age for the third dose of the primary course of immunisations was 8.5 months (schedule $3,4 \cdot 5,8 \cdot 5$ months) ${ }^{11}$ but has been 4 months since May 1990 (schedule 2, 3, 4 months). ${ }^{12}$ Thus all the study children should have completed their primary course of immunisations. The uptake of immunisation was calculated as the number of children recorded as being immunised by the end of January 
1991 expressed as the percentage of the total number of children in each study category.

The main statistical methods used in the study included a $\log$ linear modelling technique, logistic regression, ${ }^{13}$ to examine the strength of association between the uptake and the vaccination location after allowing for other important influencing factors. The $\chi^{2}$ test and a non-parametric analysis (Kruskal-Wallis one way analysis of variance) were also employed to compare the immunisation uptake state between the two study groups.

\section{Results}

A total of $1946(89.8 \%)$ of 2167 children resident in rural and suburban areas were registered at general practice surgeries for their immunisation procedures compared with $556(38.4 \%)$ of 1449 children living in inner cities (table I). The overall uptake of immunisations was greater in general practice than in child health clinics. This was so in both inner city and rural and suburban districts for both the first and the third doses of immunisations (table II).

TABLE I-Numbers (percentages) of children registered at two immunisation locations by type of district

\begin{tabular}{lccc}
\hline Type of district & General practice & Health clinic & Total \\
\hline Rural/suburban & $1946(89 \cdot 8)$ & $221(10 \cdot 2)$ & $2167(100 \cdot 0)$ \\
Inner city & $556(38 \cdot 4)$ & $893(61 \cdot 6)$ & $1449(100 \cdot 0)$ \\
\hline Total & $2502(69 \cdot 2)$ & $1114(30 \cdot 8)$ & $3616(100 \cdot 0)$ \\
\hline
\end{tabular}

TABLE II-Percentage uptake of immunisations among children registered at two vaccination locations by type of district (whole numbers in parentheses)

\begin{tabular}{clll}
\hline Type of district & General practice & Health clinic \\
\hline \multicolumn{2}{c}{ Rural/suburban: } & & \\
First dose & $\left\{\begin{array}{l}\text { Diphtheria } \\
\text { Pertussis }\end{array}\right.$ & $96 \cdot 6(1880 / 1946)$ & $93 \cdot 2(206 / 221)$ \\
Third dose & $\left\{\begin{array}{l}\text { Diphtheria } \\
\text { Pertussis }\end{array}\right.$ & $89 \cdot 3(1758 / 1946)$ & $84 \cdot 6(187 / 221)$ \\
Inner city: & $82 \cdot 7(1610 / 1946)$ & $84 \cdot 2(186 / 221)$ \\
First dose & $\left\{\begin{array}{l}\text { Diphtheria } \\
\text { Pertussis }\end{array}\right.$ & $91 \cdot 4(508 / 556)$ & $89 \cdot 9(170 / 221)$ \\
Third dose & $\begin{array}{l}\text { Diphtheria } \\
\text { Pertussis }\end{array}$ & $72 \cdot 6(487 / 556)$ & $85 \cdot 8(797 / 893)$ \\
& & $69 \cdot 4(386 / 56 / 556)$ & $68 \cdot 2(609 / 893)$ \\
\hline
\end{tabular}

We compared other aspects of uptake of immunisation against pertussis between the two groups of children, ignoring the type of district they lived in. Overall, $2502(69 \cdot 2 \%)$ of the children were registered at general practice surgeries and $1114(30.8 \%)$ at child health clinics (table I). As well as having a greater uptake of first immunisations children registered at general practices were less likely to miss the third dose of immunisation than those attending health clinics. Among the children who were immunised with the first dose of pertussis, $11 \cdot 1 \%$ of the general practice registered children (249/2245) had not received the third dose compared with $21 \cdot 1 \%$ of those $(201 / 953)$ at health clinics (table III). These differences suggested that children at health clinics were not only less likely to be immunised but also less likely to complete their full course of immunisations than those at general practice surgeries.

The children registered at general practice surgeries completed their primary vaccinations at a younger age than those at health clinics, the median ages being 11 and 13 weeks for the first dose and 24 and 29 weeks for the third, respectively (table III). Figure 1 shows that some $53 \%$ of children attending general practice surgeries had received their third pertussis vaccination before 6 months of age compared with only about $30 \%$ of children at health clinics.

Only about one third of the immunisation procedures
TABLE III-Comparative data on pertussis immunisation state among children aged 10-12 months six to eight months after primary immunisation course should have been completed) registered at general practice and health clinics

\begin{tabular}{|c|c|c|c|}
\hline Immunisation state & General practice & Health clinic & $\mathrm{p}$ Value \\
\hline \multicolumn{4}{|l|}{$\%$ Lptake (No of children): } \\
\hline First pertussis dose & $89 \cdot 7(2245 / 2502)$ & $85 \cdot 5(953$ & $<0.00$ \\
\hline Third pertussis dose & $79 \cdot 8$ & 14 & $<$ \\
\hline$\%$ (No) of children missing & & & \\
\hline $\begin{array}{l}\text { thira } \\
\text { Median }\end{array}$ & 1 & 3) & $<0.001^{\star}$ \\
\hline First p & 11 & 13 & $<0.01 \dagger$ \\
\hline Third pertussis dose & 24 & 29 & $<0.001 \dagger$ \\
\hline $\begin{array}{l}\% \text { (No) of scheduled } \\
\text { procedures of third } \\
\text { pertussis immunisation }\end{array}$ & $50 \cdot 5(1008 / 1996)$ & $31 \cdot 4(236 / 752)$ & $<0.00$ \\
\hline
\end{tabular}

* $\chi^{\prime}$ test

†Kruskal-Wallis one way analysis of variance.

†Children who received first pertussis immunisation but not third, expressed as proportion of those already immunised with first dose.

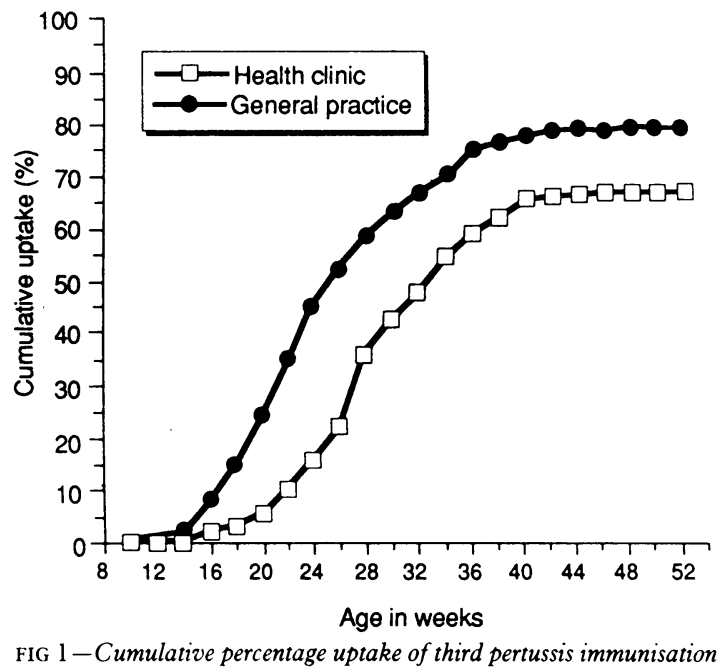
in two groups of children

given to children registered at health clinics were scheduled compared with about half of those given to children registered at general practices (table III). The remainder were recorded as unscheduled when the parents brought their children to the immunisation centre because they thought the immunisation was due or they attended for other reasons. Children, on average, received unscheduled immunisations at a later age than scheduled ones. Figure 2 shows that among the immunised children about $30 \%$ of those who received immunisation by appointment (scheduled immunisation) were vaccinated after 6 months of age compared with nearly $45 \%$ of those who had been immunised opportunistically (unscheduled immunisation).

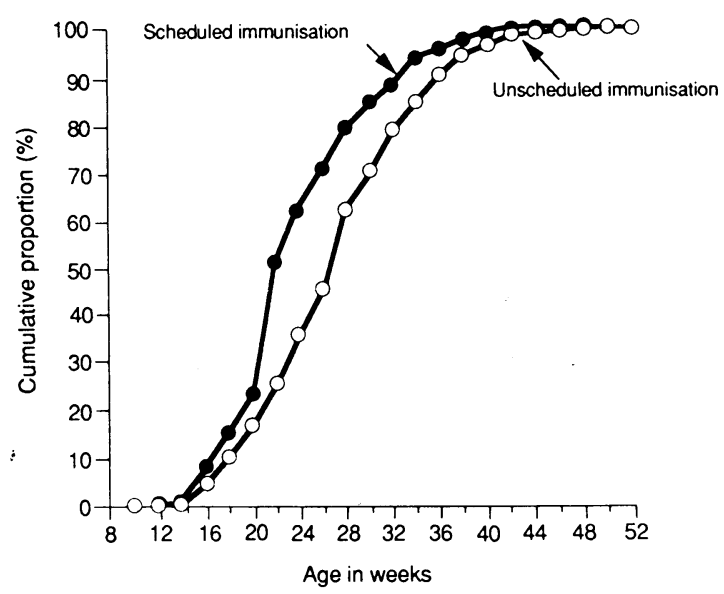

FIG 2-Cumulative proportion of children immunised with third pertussis dose by age 
When children moved among districts a higher proportion registered with child health clinics than with general practitioners. This resulted in $22.5 \%$ of health clinic children being "movements in" (251 1114) compared with $11.4 \%$ of children attending general practitioners $(285 / 2502)$. We considered this factor together with type of district in a multivariate analysis to study the strength of the association of immunisation uptake with vaccination location. Table IV shows the odds ratios of not being immunised with the third dose of pertussis, estimated from a fairly well fitted logit model ${ }^{13}$ for each stated factor after controlling for the others. The odds of not being fully

TABLE IV-Odds ratios of not being immunised with third pertussis dose estimated from logit model ${ }^{\star}$ for each stated factor after controllin for others with larger sample $95 \%$ confidence intervals

\begin{tabular}{lcc}
\hline Factor & Odds ratio & $95 \%$ Confidence interval \\
\hline $\begin{array}{l}\text { Vaccination location: } \\
\quad \text { General practice }\end{array}$ & 1.0 & \\
$\quad$ Health clinic & 1.4 & 1.1 to 1.6 \\
$\begin{array}{l}\text { Type of district: } \\
\text { Rural/suburban }\end{array}$ & 1.0 & \\
$\quad \begin{array}{l}\text { Inner city } \\
\text { Resident: }\end{array}$ & 3.0 & 2.4 to 3.6 \\
$\quad$ At birth & 1.0 & \\
Moving in & 1.2 & 0.9 to 1.5 \\
\hline
\end{tabular}

${ }^{\star}$ Likelihood ratio $\chi^{2}=4 \cdot 7 ; \mathrm{df}=4 ; \mathrm{p}=0 \cdot 32$.

immunised among children registered at a health clinic were 1.4 times greater than those among children registered at a general practice, and the odds were 3.0 times greater among children resident in inner city districts than their counterparts resident in rural and suburban areas. Children who had moved into a district from outside, however, were not at substantially higher risk of not being vaccinated than those who had been resident in the district since birth (table IV).

\section{Discussion}

Our findings suggest that children registered at child health clinics were less likely to be immunised and less likely to be vaccinated at the recommended age than those registered at general practice surgeries. Alberman et al suggested that the difference in uptake of immunisation between vaccination locations might reflect sociodemographic differences between families who use general practice and those who use community child health clinics. ${ }^{14}$ Others have also reported the difference in the uptake of immunisation among different minority ethnic groups, ${ }^{15}$ and among different social classes. ${ }^{6}$ We were not able to investigate this issue as social data are not currently available in the computer system.

We found that more children registered at genera practice surgeries attended for the appointed immunisation sessions (scheduled immunisations) than those at health clinics, indicating that the parents of the children registered at general practice surgeries were more likely to receive the immunisation appointments and to be reminded, when necessary, to take their children to attend for immunisations ${ }^{6}$ or were more likely to respond to the appointments. It may be that, apart from other possible reasons, immunisation times at general practice surgeries were more flexible and more convenient for the families, especially for working parents.

Our results confirmed that uptake of immunisation was poorer in inner city areas, a finding that has been reported before using a different database. ${ }^{5}$ Inner city families face adverse factors which can affect, among other outcomes, the uptakes of childhood immunisation. ${ }^{16}$ Vaccination location appears to be a contributory influence.

Jarman et al have pointed out that general prac- titioners with high case loads, those working in singlehanded practice, and elderly general practitioners are less likely to obtain high uptake of immunisations. ${ }^{5}$ This might partly explain our finding that uptake among children at general practice surgeries was higher in rural and suburban than in inner city areas. There were no data in this study on individual general practitioners to allow direct investigation of this possibility.

A high uptake (nearly 90\%) of the first dose of $\frac{?}{c}$ primary course at both locations in both types of $\vec{F}$ districts was found in our study, suggesting that contraindications to vaccination could not be the excuse for overall lower uptake of immunisations. The $\frac{\bar{\sigma}}{\bar{c}}$ hypothesis that in general mobility of a child population $\overrightarrow{\widetilde{\sigma}}$ is associated with a lower probability of children $\supseteq$ receiving immunisations ${ }^{1}$ was not confirmed by our wै study. This might reflect the new ease of data transfer $\vec{\circ}$ associated with computerised systems, especially those that are interactive, like the one we studied, and $\vec{\omega}$ the encouragement for general practitioners to transfer? records quickly because of the targeting provisions of 3 . the new general practitioner contract which becamew operative in April 1990.

This study was based on data from the North Easto Thames Regional Interactive Child Health System, and each individual child was treated as a basic study $\overrightarrow{ }$ unit. It is possible that the mix of social class and ethniccu group was different between our general practice and child health clinic study populations. We were not able to investigate this possible source of bias in our results. $N$ Social class and ethnic group, however, are not the only응 factors associated with uptake rates. ${ }^{56}$ We found thato nearly $90 \%$ of children resident in rural and suburban districts were registered at general practice surgeries. for immunisations compared with only $38 \%$ of those living in inner cities (table I). Could this difference,.among other factors, also contribute to the overallo lower uptake rates in inner city areas? Previous studiess focused mainly on ethnic group and social class and $\overline{0}$ tried to explain lower uptake rates in inner city areas with the different mix in these factors. ${ }^{5}$ Little attention ${ }_{\mathcal{Q}}^{\Phi}$ was paid to the possible contribution of immunisation location to the variance of immunisation uptake. Our? findings can be viewed as generating a hypothesis for further study on this topic, especially allowing for other factors such as ethnic origin and social class of children.

This child health computer system allows rapid and easy analysis of data on preventive child care with the possibility of rapid feedback to permit improved performance. In addition, such a child health com-O puting system can provide reliable and useful information on the child health services. ${ }^{14}$ Our findings have? the following implications. Firstly, a topic for further investigation was generated that immunisation $>$ location could be a major contributory factor to․ㅡㅇ. immunisation uptake in childhood. Secondly, immunisation uptake rate may be increased with additional support and encouragement to enable ${ }^{\omega}$ general practitioners to undertake immunisations, especially in inner city areas where uptake is low. And, thirdly, the data derived from child health computinges systems, especially if sociodemographic data-for example, social class, ethnic group - can be collected, could be used for rapid, ongoing, and comprehensiven epidemiological assessment of child health servicee⿱ programmes without the need for expensive and $\frac{\varrho}{0}$ difficult "one off" surveys.

This study is part of a project evaluating the regiona interactive child health computing system funded by North East Thames Regional Health Authority. We thank all the participant health districts for permission to use their child health data, Mrs $\mathrm{H}$ Horne and Mrs M Homersham at the North East Thames Regional Health Authority's computer 
centre, staff at the computer centre at the Royal Free Hospita School of Medicine, and Drs E M Boothroyd-Brooks and A Lloyd-Evans for advice.

1 Riley DJ, Mughal MZ, Roland J. Immunisation state of young children admitted to hospital and effectiveness of a ward based opportunistic admitted to hospital and effectiveness

2 Nicoll A, Elliman D, Begg NT. Immunisation: causes of failure and strategies and tactics for success. BMF 1989;299:808-12.

3 Bussey AL, Holmes BS. Immunisation levels and the computer. Lance $1978 ;$;i: 450 .

4 Begg NT, Noah ND. Immunisation targets in Europe and Britain. BMf 1985;291:1370-1

5 Jarman B, Bosanquet N, Rice P, Dollimore N, Leese B. Uptake of immunisation in district health authorities in England. BMF 1988;296: 2775-8.

6 Peckham C, Bedford H, Senturia Y, Ades A. National immunisation study: factors infuencing immunisation uptake in childhood. The Peckham report. London: Action Research for the Crippled Child, 1989.

7 Lingam S, Miller CL, Pateman J. Role of an immunisation advisory clinic. BMF 1986;292:1717-9.
8 Roper J, Day S. Uptake of immunisations in low birthweight infants. Arch D. Child 1988;63:518-21.

9 Child Health Computing Committee. The child health system - an introduction. Cardiff: Welsh Health Services Authority, 1983.

10 Walker CHM. "Batch" or "on-line" for child health-a review. $B M$ 1980;281:1400-1.

11 Department of Health and Social Security. Immunisation against infectiou diseases. London: HMSO, 1988.

12 Department of Health. Immunisation against infectious diseases. London HMSO, 1990.

13 Norusis MJ. Log-linear models. In: SPSS-X advanced statistics guide. Chicago: SPSS Inc, 1985:327-65.

14 Alberman E, Watson E, Mitchell P, Day S. The development of performance and cost indicators for preschool immunisation. Arch Dis Child 1986;61: 251-6.

15 Baker MR, Bandaranyake R, Schweiger MS. Differences in rate of uptake in immunisation among ethnic groups. BMF 1984;288:1075-8.

6 Rice $\mathrm{P}$, Irving $\mathrm{D}$, Davies $\mathrm{G}$. Information about district health authorities in England from the 1981 census. London: King's Fund, 1984.

\section{A PAPER THAT CHANGED MY PRACTICE}

\section{Hospital acquired infection}

I have never forgotten the impact made on me by a full page colour plate and its caption and the title of an accompanying editorial. They were published in the American Fournal of Diseases of Children 30 years ago. These arresting pieces of medical journalism seemed designed to educate the junior hospital doctor with little time for critical reading of the medical literature. They certainly changed my outlook on patient care.

The picture was of a 7 day old infant born eight weeks before term; it was taken minutes before her death. You could be forgiven for thinking that she looked quite healthy, for her head, neck, and upper chest were the colour of a ripe peach. But milk was dribbling from one corner of her mouth, and her abdomen, not shown in full, looked a little distended. The rosy hue of the upper part of her body had a clear line of demarcation, which was in fact the rapidly spreading edge of indurated erythema. Achromobacter (of which I had never heard) had been isolated from her bloodstream. Achromobacter is a genus which seems to come and go in successive editions of "Bergey"; a dumping ground of the past, perhaps, and Acinetobacter and Alcaligenes may now be more familiar. But these and other organisms with equally strange names flourish in water, and "Water bugs in the bassinet" was the editorial title which also caught my eye. The range of Gram negative bacteria capable of living in water and hence in the humidification units of equipment such as incubators, suction apparatus, and so on was vividly described. The threat they posed to the inhabitants of intensive care units, neonatal and otherwise, was to become much better known later in the 1960s and 1970 as equipment there became more complex. These and all other hospital acquired infections continue to be responsible for both mortality and morbidity, and impose an economic burden on health services.

How did John Foley and his colleagues working in Kansas City and the editor of the journal (Warren Wheeler) change my practice? Perhaps not quite in the way the originator of this series envisaged. I decided then that I would try and learn as much as I could about neonatal bacterial infection and how to prevent it so as to avoid as far as possible these tragedies. I came to appreciate to the full the enormous help microbiologists and their technical staff give their clinical colleagues and how much we can learn from them. I hope my patients benefited just a little. - PAMELA A DAVIES, formerly honorary consultant physician, Hammersmith Hospital, London

Foley JF, Gravelle CR, Englehard WE, Chin TDY. Achromobacter septicemia - fatalities in prematures. 1. Clinical and epidemiological study. Am f Dis Child 1961;101:279-88.

Anonymous. Water bugs in the bassinet [Editorial]. Am $f$ Dis Child 1961;101:273-7.

\section{THE MEMOIR CLUB}

If you deal with serious, potentially fatal, diseases, at whatever stage of advancement they may present, you are bound to become acquainted with death. We only die once but we must all do it; Palmerston said: "Die, my dear Doctor, that's the last thing I shall do." Hesitation to talk about what must be only tends to create mystery, to increase fear, and to promote illusion. Evasion of the subject of death during health will be no help to any of us when our time comes. We will be sorry to go, it is good to be alive, we hold on to existence even if we are one of those who comfort themselves with the expectation of another life to come. However, it is no bad thing as you grow older to be a little prepared for the inevitable and it is wise not to be too morose about it. A well known comedian standing next to an actor aged 90 at a funeral asked him how old he was and on being told said, "It's hardly worth your while going home."

I have stood by deathbeds with many a good ward sister (the finest flowering of the nursing profession), have told many people, when asked, that their time was near, and have encouraged others to hope to the end according to my reading of their need. Most often no words have been required. It has seemed to me that to maintain dignity is much more important in dying than in living. I hope to die in my own bed, in reasonable comfort (I have a good doctor), with some of my family to say a cheerful farewell and with any luck to have a last laugh with them, but I will take it where, when, and how it comes because I must. D Johnson said: "It matters not how a man dies, but how he lives. The act of dying is not of importance, it lasts so short a time." Fortunately as old friends and relatives go, even if they have become weak and feeble in mind and body, good memories take us back at once to their prime. I shall hope for agile memories in those I love and little distress because they know what fun I have had in living. The discomforts of passing are soon forgotten. Let us (for Heaven's sake!) face the matter with as good a grace as we can muster.

From Not a Moment to Lose by David Smithers. Published under the BMF's Memoir Club imprint. ISBN 0727902784 Price: Inland 114.95 ; abroad $£ 17.50$. BMA members: Inland $£ 13.95$; abroad $£ 16.50$. 